\title{
G4. INTEGRATING QUALITY BY DESIGN INSIDE QUALITY MANAGEMENT TECHNOLOGY TRANSFER PROJECTS IN BIOPHARMACEUTICAL INDUSTRY.
}

\author{
Alexander da Silva Neves ${ }^{1}$; Elezer Monte Blanco Lemes ${ }^{1}$. \\ ${ }^{1}$ Bio- Manguinhos / Fiocruz.
}

INTRODUCTION The Project Quality Management seeks to ensure that a project meets the customer's needs and involves all project activities during its life cycle. However, in technology transfer projects within the biopharmaceutical industry, the quality can not be measured only by the final product. Even if the product meets specifications, the absorption of knowledge and process parameters originated from scientific nature shall be documented and transferred to the technology absorber, so that it can internalize the activities in their routine production. With the creation of the International Conference on Harmonization - ICH 1990, it became possible to stablish a guideline to the study of factors affecting the safety, quality, effectiveness and multidisciplinarity of products in manufacturing processes as critical attributes. One of the regulatory practices that have been implemented is the Quality by Design (QbD) where, through a systematic approach to development, is emphasized the science and the risk management of quality, to ensure that the quality of a product is built in production processes from the beginning, rather than to be tested only at the end.

OBJECTIVE This paper aims to describe the use of $\mathrm{QbD}$ in quality management of a technology transfer project for a biopharmaceutical product, in order to minimize risks to the construction of product quality during the project execution.

METHODOLOGY The methodology is based on a case study, with the data collection source document research in reference guides and international laws, in which the main steps are mapped for the implementation of the $\mathrm{QbD}$ guidelines. After mapping the critical steps, Quality Target Product Profile (QTPP), Critical Quality Attributes (CQA) and Design Space will be outlined for the product, in the project quality management.

RESULTS The use of QbD steps will enable the knowledge of variables and process critical parameters, design space and comparability between processes involving 
companies in technology transfer. With this, throughout the project it will be possible to see gaps that may influence negatively in the management of the product life cycle in each project phase.

CONCLUSION The application of the QbD tool will allow the formation of a model with scientific principles in the quality management of a biopharmaceutical technology transfer project that will assist in the construction of the QTPP during the phases of the project. With this, the expectation is to provide a more efficient construction of quality, facilitating compliance with regulatory requirements, reducing thus risk of delays and rework during project execution.

KEYWORDS project management, QbD, risk management, technology transfer. 